\title{
Adventitious Bud Induction and Plant Regeneration from Stem Nodes of Salvia splendens 'Cailinghong'
}

\author{
Ling Yu, Hongwei Chen, Peipei Hong, Hongli Wang, and Kefeng Liu ${ }^{1}$ \\ Laboratory of Salvia splendens, College of Urban and Rural Development, \\ Beijing University of Agriculture, Beijing 102206, China
} Additional index words. adventitious bud, cultivar, direct induction, plant growth regulators,
Salvia splendens

\begin{abstract}
Salvia splendens is a widely used ornamental bedding plant; however, the limited propagation method has decreased its quality and yield. Through years of selection, we have obtained a new variety of $S$. splendens with weak apical dominance and named it as 'Cailinghong'. To establish an effective method for regeneration of $S$. splendens 'Cailinghong', different explants, including leaves, receptacles, petioles, stem nodes, and stem segments were used for adventitious bud induction. Next, various combinations of plant growth regulators (PGRs) were selected for bud and root induction, which were assessed by adventitious bud initiation rate and proliferation rate, as well as root induction rate. Meanwhile, the survival rate of transplanted plantlets was also calculated. As a result, stem nodes were found easy to be induced to form buds, and the optimum medium component was 1/2 Murashige and Skoog (MS) medium supplemented with $0.45 \mu \mathrm{M}$ naphthalene acetic acid (NAA), $8.88 \mu \mathrm{M}$ 6-benzylaminopurine (6-BA), and $2.46 \mu \mathrm{M}$ 3-indolebutyric acid (IBA) for plantlets induction, whereas $1 / 4$ MS medium supplemented with $2.23 \mu \mathrm{M}$ NAA for root induction. Furthermore, the survival rate of transplanted plantlets was up to $80 \%$, and all regenerated plantlets were normal in phenotype. Therefore, cultured in 1/2 MS medium with combined PGRs, whole plantlet of $S$. splendens 'Cailinghong' could be regenerated directly from stem node.
\end{abstract}

Among all the numerous ornamental bedding plants, due to its bright colors and long florescence, $S$. splendens belonging to Labiatae family, is most widely planted in gardens, flowerbeds, and by roadsides (Soundararajan et al., 2013). With the development of research and technology, the breeding of $S$. splendens has been largely improved (Liu et al., 2012), and many new varieties have been cultivated, such as $S$. splendens 'Zhongchuanhong', a tall variety breed (Hui et al., 2004), and S. splendens 'Shenzhouhong', a variety produced through space breeding (Fu et al., 2009).

It has been reported that, wild type $S$. splendens as well as its new varieties need to remove the terminal bud three or four times to

Received for publication 4 Sept. 2014. Accepted for publication $7 \mathrm{Jan} .2015$.

This study was supported by the Beijing Municipal Commission of Education-Science and Technology Project (PXM2014_014207_000001), Scientific Research Quality Improvement Project of the Beijing University of Agriculture (GZL-2013007), and Youth Science Foundation of the Beijing University of Agriculture (2117516004).

We wish to express our heartfelt thanks to Fenghe (Shanghai) Information Technology Co., Ltd. Their ideas and help gave a valuable added dimension to our research.

The authors have declared that no competing interests exist.

${ }^{1}$ To whom reprint requests should be addressed; e-mail kefengliu67@hotmail.com. meet the product requirements (Zhi et al., 2013). Through years of selection, we have found a new variety with weak apical dominance and named it as 'Cailinghong'. Its original lateral branch develops into the first lateral branch during vegetative growth phase, which further develops into multilevel lateral branches. 'Cailinghong' grows and develops without the need of manual removal of the terminal bud during its whole life. At last, it forms a naturally low and spherical type plant with multilevel lateral branches and blossom exuberant, which is more suitable for landscaping. As far as we know, there is no other variety of $S$. splendens having such powerful branching ability as 'Cailinghong' does. In addition, related report about its tissue culture remains rare.

However, there are still many problems in the development of $S$. splendens, such as limited colors, serious pests, and diseases, which will inevitably lead to a decrease in yield and a decline in flower quality. What is more, S. splendens shows higher requirements on temperature, which adds difficulties on its reproduction (Lai et al., 2001). Thus, it is of great importance to investigate proper rapid propagation technique of $S$. splendens.

Recently, an indirect regeneration method that uses the callus of $S$. splendens has been reported. Unfortunately, the regeneration cycle is comparatively long. Moreover, under in vitro conditions, because of long-term exposure to PGRs and chemicals, the callus cells are very sensitive (Maruthi Rao et al., 2012), and they can exhibit abnormal morphological characteristics and somaclonal variation. Direct regeneration by organogenesis is an alternative method, referring to the culture of different tissues in vitro such as buds, leaves, stems, and roots, to develop new shoots (Mallón et al., 2011). In all, it is an effective method of mass propagation of plants, while there is no need for callus as an intermediate stage.

In this study, explants (receptacle, leaf, petiole, stem segment, and stem node) were selected to establish an effective method for regeneration of $S$. splendens 'Cailinghong'. Then the effects of PGRs on adventitious bud induction and shoot regeneration were evaluated. The results may provide clues for further application of biotechnology on regeneration of $S$. splendens 'Cailinghong'.

\section{Materials and Methods}

Plant materials. S. splendens 'Cailinghong' was purchased from Zhejiang Hongyue Flower Co. Ltd (Hangzhou, Zhejiang, China). Explants (receptacles, leaves, petioles, stem nodes, and stem segments) were obtained from 2- to 4month-old mature 'Cailinghong' grown in the greenhouse $\left(22 \pm 2{ }^{\circ} \mathrm{C}\right.$ with humidity of $60 \%$ ).

Selection of explants. Receptacles were obtained from flower bud whose height was about $1 \mathrm{~cm}$. Leaves, petioles, and stems were collected from tender branches and leaves of the collected stem nodes were removed. Then explants of leaf were cut into small pieces of $5 \mathrm{~mm} \times 5 \mathrm{~mm}$, and explants of petiole, stem node, and stem segment were cut into small pieces of 5 to $9 \mathrm{~mm}$. In this way, each stem node only contained two axillary buds. Explants were surface sterilized by $75 \%(\mathrm{v} / \mathrm{v})$ ethanol for $30 \mathrm{~s}$, then by $1 \%(\mathrm{v} / \mathrm{v})$ sodium hypochlorite for $1 \mathrm{~min}$, and finally rinsed with sterile distilled water for three times (3 min each time). Three explants of receptacle, leaf, petiole, stem node, or stem segment were planted in each glass vessel (five glasses for each type of explant). All explants were cultured in glass vessels that contained $1 / 2 \mathrm{MS}$ basal culture medium (Murashige and Skoog, 1962) without PGRs. The initiation rate was observed and calculated: Initiation rate $=($ No. of initiated explants/No. of inoculated explants) $\times$ $100 \%$.

Induction of adventitious bud. By calculating the initiation rates of different types of explants, the explant with the highest initiation rate was chosen as the optimal explant. Then the overall experiment of all the possible combinations was designed and the sterilized optimal explants were placed on $1 / 2$ MS medium ( $\mathrm{pH}$ 5.8) supplemented with different concentrations and combinations of NAA $(0,0.45$, or $2.23 \mu \mathrm{M}), 6$-BA $(4.44$, 8.88 , or $22.20 \mu \mathrm{M})$, and IBA $(0,2.46$, or $4.92 \mu \mathrm{M}$ ) to determine the optimum medium for adventitious bud induction (Soundararajan et al., 2013). The concentrations of 13.32 and $17.76 \mu \mathrm{M}$ 6-BA were excluded because 
there were no significant changes at 13.32 and $17.76 \mu \mathrm{M}$ when compared with $8.88 \mu \mathrm{M}$ 6-BA in the pre-experiment. In total, 27 treatments were generated and 3 replicates (15 explants for each replicate) were performed for each treatment. After 3 weeks of tissue culture, the differentiation rate and proliferation rate were calculated to measure the growth conditions of explants and confirm the optimal concentration and combination of NAA, 6-BA, and IBA. Differentiation rate $=($ No. of differentiated explants $/$ No. of inoculated explants) $\times 100 \%$. Proliferation rate $=$ (No. of buddings $/$ No. of inoculated explants) $\times 100 \%$. All the chemical reagents were purchased from Sigma-Aldrin $\mathrm{GmbH}$ (Munich, Germany), and the medium was first sterilized using the MLS-3780 autoclave (Sanyo, Japan) before being used. The culture condition was $14 \mathrm{~h}$ photoperiod with illumination of $300 \mu \mathrm{mol} \cdot \mathrm{m}^{-2} \cdot \mathrm{s}^{-1}$ at $25 \pm 2{ }^{\circ} \mathrm{C}$, $60 \%$ RH (relative humidity).

Plant regeneration. Adventitious buds were cultured in the same medium for subculture after induction from explants for 3 to 5 weeks. When the regenerated shoots grew to 2 to $3 \mathrm{~cm}$ (about three leaf segments), they were transferred to the autoclaved inducing medium and cultured under $16 \mathrm{~h}$ photoperiod with illumination of $300 \mu \mathrm{mol} \cdot \mathrm{m}^{-2} \cdot \mathrm{s}^{-1}$ at $25 \pm 2{ }^{\circ} \mathrm{C}, 60 \% \mathrm{RH}$. The medium contained 1/4 MS medium that was supplemented with various concentrations of NAA $(0,2.23,4.46,11.15$, or $22.29 \mu \mathrm{M})$. Root induction frequency was recorded and calculated: Root induction frequency $=$ (No. of rooted explants/No. of inoculated explants) $\times 100 \%$.

After 5 to 6 weeks, when the height of plantlets reached above $8 \mathrm{~cm}$ and root length over $3 \mathrm{~cm}$, they were moved into plastic pots $(70 \mathrm{~mm} \times 65 \mathrm{~mm} \times 80 \mathrm{~mm})$ in greenhouse
(22 to $26{ }^{\circ} \mathrm{C}$ ) with culture medium for $2 \mathrm{~d}$. After removing agar from roots by gentle wash, the plants were transplanted into pots containing vermiculite and perlite $(\mathrm{v} / \mathrm{v}=2 / 1)$, which had been autoclaved at $121{ }^{\circ} \mathrm{C}$ under $1.1 \mathrm{~kg} \cdot \mathrm{cm}^{-2}$ pressure for $60 \mathrm{~min}$. Two weeks later, the survival rate of transplants was calculated and the survived plants were transplanted into larger garden pots $(130 \mathrm{~mm} \times$ $90 \mathrm{~mm} \times 110 \mathrm{~mm})$. Survival rate $=($ No. of survived plants/No. of plants moved into pots in greenhouse) $\times 100 \%$.

Statistical analysis. All the experiments were repeated three times and the data were expressed as mean \pm SE. Differences between the means were compared by analysis of variance (ANOVA) followed by Duncan's multiple range tests (Duncan, 1955) at the 0.05 level, using SAS V8.02 (SAS Institute Inc., Caly, NC). Quadratic regression analysis was also performed to detect the induction effect changing with PGRs concentrations.

\section{Results and Discussion}

Selection of explants. Our results showed that leaves exhibited no significant morphological changes, and formed neither buds nor callus; whereas receptacles, petioles, stem nodes, and stem segments exhibited significant morphological changes, formed small buds and enlarged stem bases (Table 1). In addition, stem segments could slowly form a few buds and could easily brown. Furthermore, the initiation rate of stem nodes was the highest (93.45\%) (Fig. 1A), that of stem segments was the second highest $(65.25 \%)$, and that of petioles was the lowest $(15.95 \%)$ among all explants. Previous study has shown that the stem nodes with axillary buds have several advantages, such as easy operation, maintenance of the stability of important agronomic traits, short regeneration cycle, and high regeneration rate, and have been widely used in tissue culture (Han et al., 2006; Zhang et al., 2010). Therefore, stem node was the most suitable explant for adventitious bud induction.

Effects of PGRs on bud induction. Different combinations of PGRs were adopted to investigate the optimum culture medium for bud formation. The results showed that the differentiation and proliferation rates of stem nodes increased significantly with the increase of 6-BA concentration from 4.44 to $8.88 \mu \mathrm{M}$. However, when the concentration further increased to $22.20 \mu \mathrm{M}$, the differentiation and proliferation rates decreased significantly (Table 2 ). The quadratic regression equations were: differentiation rate $=20.283 \times$ $6-\mathrm{BA}+11.129 \times$ IBA $-0.737(6-\mathrm{BA})^{2}-$ $60.839\left(R^{2}=0.857\right)$; proliferation rate $=$ $33.8046 \times 6$-BA $+18.585 \times$ IBA $-1.228 \times$ $(6-\mathrm{BA})^{2}-101.492\left(R^{2}=0.857\right)$. In addition, the variance analysis indicated that stem nodes showed the highest differentiation rate in mediums supplemented with $0.45 \mu \mathrm{M}$ NAA, $8.88 \mu \mathrm{M}$ 6-BA, and $2.46 \mu \mathrm{M}$ IBA

Table 1. The selection of explants.

\begin{tabular}{lcl}
\hline Explants & $\begin{array}{c}\text { Initiation } \\
\text { rate }(\%)\end{array}$ & \multicolumn{1}{c}{ Characteristics } \\
\hline Receptacle & $23.2 \pm 1.4 \mathrm{~d}$ & Few small buds \\
Leaf & $31.7 \pm 1.2 \mathrm{c}$ & No obvious change \\
Petiole & $16.0 \pm 1.1 \mathrm{e}$ & Few small buds \\
Stem node & $93.5 \pm 1.1 \mathrm{a}$ & Some small buds \\
Stem segment & $65.3 \pm 1.3 \mathrm{~b}$ & Stem base enlarged \\
\hline
\end{tabular}

Values presented as mean $\pm \mathrm{SE}$, differences were compared with Duncan's multiple range test, and the values followed by the same letter are not significantly different $(\alpha=0.05)$.
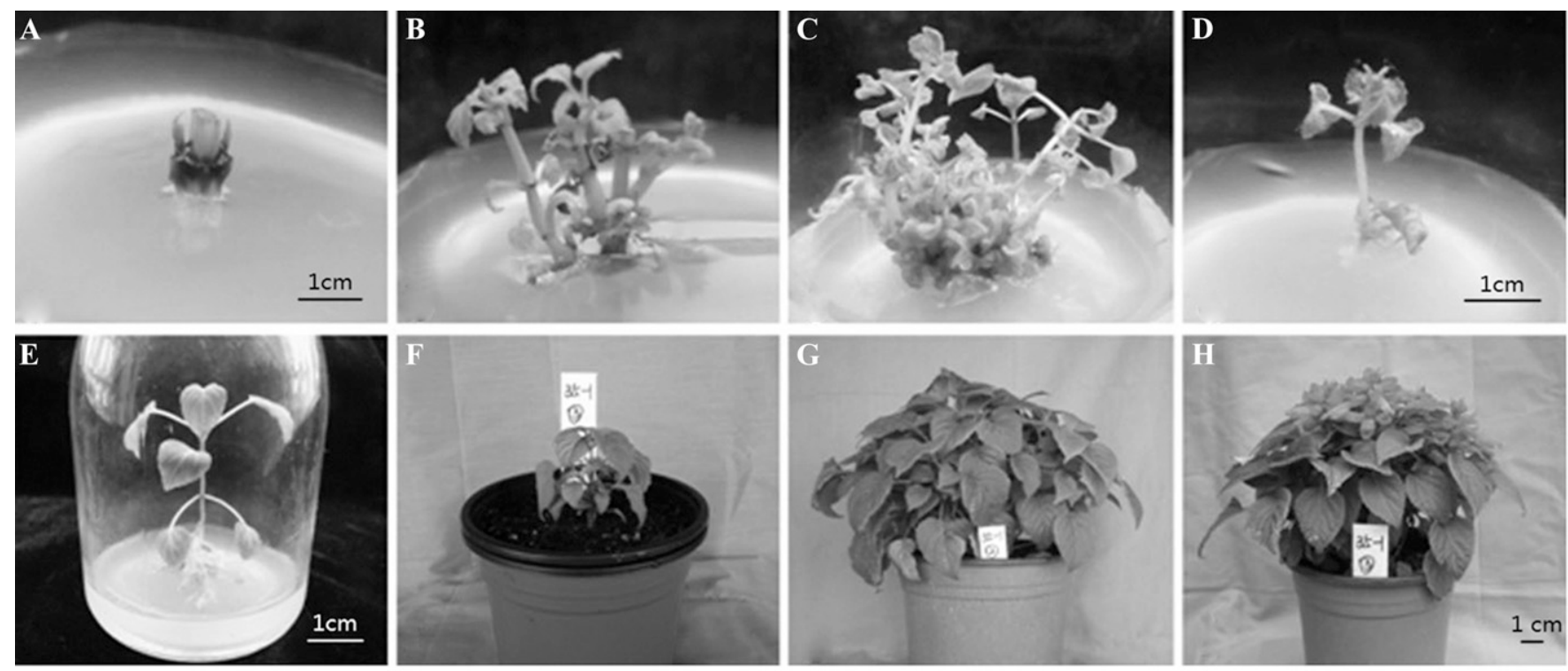

Fig. 1. Plant regeneration from stem nodes of 'Cailinghong'. (A) Bud induction from stem nodes with axillary buds. (B) Induced buds of 'Cailinghong'. (C) Shoot proliferation of 'Cailinghong'. (A), (B), and (C) were all cultured in 1/2 MS medium supplemented with $0.45 \mu \mathrm{M}$ naphthalene acetic acid (NAA), $8.88 \mu \mathrm{M}$ 6-benzylaminopurine, and $2.46 \mu \mathrm{M} 3$-indolebutyric acid. (D) Root induction from the regenerated plantlets. (E) Whole plants regenerated in the root-inducing medium. (D) and (E) were cultured in 1/4 MS medium supplemented with $2.23 \mu \mathrm{M} \mathrm{NAA}$. (F), $(\mathbf{G})$, and $(\mathbf{H})$ regenerated plants grow in a greenhouse. 
(Table 3; Fig. 1B and C). Combining with quadratic analysis and variance analysis, our results indicated that 6 -BA $(P<0.01)$ was the most important PGR and IBA $(P<0.05)$ was the second most, whereas NAA $(P=$ 0.676 ) showed no significant effects on differentiation and proliferation rates of $S$. splendens. Thus, we could infer that 6-BA and IBA play important roles in shoot multiplication of $S$. splendens. This is consistent with other studies that showed that 6-BA is effective in bud proliferation inducing in many plant species, such as Guadua angustifolia (Jiménez et al., 2006), Andrographis paniculata (Purkayastha et al., 2008), Ilex glabra (Sun et al., 2010), and Chrysanthemum morifolium (Song et al., 2011). Cytokinins, including 6-BA, have shown to be able to induce the formation of shoot apical meristems during shoot organogenesis (Sugiyama, 1999). Although 6-BA has been proved to be effective in inducing shoot multiplication in S. splendens, it inhibited bud proliferation at high concentration. Similar results have been observed in Spathiphyllum floribundum (Werbrouck et al., 1995, 1996). Moreover, because of its stability, IBA was among the list of extensively used auxins as well. It is reported that high ratio of 6-BA and IBA tends to facilitate bud induction, whereas low ratio is favorable for root induction (Guo et al., 2012), which was consistent with our findings. Therefore, stem nodes were easy to be induced to form buds and the medium supplemented with $0.45 \mu \mathrm{M}$ NAA, $8.88 \mu \mathrm{M} 6$-BA, and $2.46 \mu \mathrm{M}$ IBA was the optimal medium for bud formation and proliferation.

Induction of roots. The regenerated plantlets were transferred into root-inducing medium for root development when they grew to 2 to $3 \mathrm{~cm}$ height (Fig. 1D). The results showed that, only $1.3 \%$ of regenerated plantlets have initiated roots when cultured in medium without PGRs, whereas $89 \%$ to $90 \%$ of regenerated plantlets inducted roots when cultured in medium supplemented with NAA (Table 4; Fig. 1E). Thus, NAA was effective in root induction, and the supplement of NAA to $1 / 4 \mathrm{MS}$ medium could significantly raise root induction rate. As there was no significant difference in the rates among different NAA concentrations, $2.23 \mu \mathrm{M}$ NAA was selected for root induction. The effectiveness of NAA in adventitious root induction has been reported in regenerated shoots of many plant species, including Adenosma glutinosum (Linn.) (Tu et al., 2014).

Transplantation of plantlets. There were $\approx 3$ to 5 microshoots generated in each pot with a height of 3 to $5 \mathrm{~cm}$. Two weeks later after the transplantation into pots with soil mixed with vermiculite and perlite, the survived seedlings were transplanted into larger garden pots under natural conditions (Fig. 1F). The survival rate of transplanted plantlets was up to $80 \%$, and all regenerated plantlets were normal in phenotype (Fig. $1 \mathrm{G}$ and $\mathrm{H}$ ).

Table 2. Bud differentiation rate and proliferation rate from stem nodes of Salvia splendens when cultured in medium with various combinations of plant growth regulators (NAA, 6-BA, IBA).

\begin{tabular}{|c|c|c|c|c|c|}
\hline Treatment & NAA $(\mu \mathrm{M})$ & $6-\mathrm{BA}(\mu \mathrm{M})$ & IBA $(\mu \mathrm{M})$ & $\begin{array}{c}\text { Differentiation } \\
\text { rate }(\%)\end{array}$ & $\begin{array}{l}\text { Proliferation } \\
\text { rate }(\%)\end{array}$ \\
\hline 1 & 0 & 4.44 & 0 & $29.0 \pm 0.6 \mathrm{i}$ & $48.3 \pm 1.0 \mathrm{i}$ \\
\hline 2 & 0.45 & 4.44 & 0 & $19.0 \pm 0.6 \mathrm{j}$ & $31.5 \pm 1.0 \mathrm{j}$ \\
\hline 3 & 2.23 & 4.44 & 0 & $19.0 \pm 0.6 \mathrm{j}$ & $31.5 \pm 1.0 \mathrm{j}$ \\
\hline 4 & 0 & 4.44 & 2.46 & $24.0 \pm 0.6 \mathrm{i}$ & $40.0 \pm 1.0 \mathrm{i}$ \\
\hline 5 & 0.45 & 4.44 & 2.46 & $24.0 \pm 0.6 \mathrm{i}$ & $40.0 \pm 1.0 \mathrm{i}$ \\
\hline 6 & 2.23 & 4.44 & 2.46 & $22.7 \pm 0.3 \mathrm{i}$ & $37.8 \pm 0.5 \mathrm{i}$ \\
\hline 7 & 0 & 4.44 & 4.92 & $23.7 \pm 0.3 \mathrm{i}$ & $39.4 \pm 0.6 \mathrm{i}$ \\
\hline 8 & 0.45 & 4.44 & 4.92 & $27.3 \pm 0.3 \mathrm{~h}$ & $45.6 \pm 0.6 \mathrm{~h}$ \\
\hline 9 & 2.23 & 4.44 & 4.92 & $24.7 \pm 0.3 \mathrm{hi}$ & $41.1 \pm 0.6 \mathrm{hi}$ \\
\hline 10 & 0 & 8.88 & 0 & $47.0 \pm 0.6 \mathrm{e}$ & $78.3 \pm 1.0 \mathrm{e}$ \\
\hline 11 & 0.45 & 8.88 & 0 & $50.7 \pm 0.3 \mathrm{~g}$ & $84.4 \pm 0.6 \mathrm{~g}$ \\
\hline 12 & 2.23 & 8.88 & 0 & $31.3 \pm 1.5 \mathrm{~g}$ & $52.2 \pm 2.4 \mathrm{~g}$ \\
\hline 13 & 0 & 8.88 & 2.46 & $82.7 \pm 1.5 \mathrm{~b}$ & $137.8 \pm 2.4 \mathrm{~b}$ \\
\hline 14 & 0.45 & 8.88 & 2.46 & $85.7 \pm 0.7 \mathrm{a}$ & $142.8 \pm 1.1 \mathrm{a}$ \\
\hline 15 & 2.23 & 8.88 & 2.46 & $81.0 \pm 1.0 \mathrm{~b}$ & $135.0 \pm 1.7 \mathrm{~b}$ \\
\hline 16 & 0 & 8.88 & 4.92 & $76.7 \pm 0.9 \mathrm{c}$ & $127.7 \pm 1.5 \mathrm{c}$ \\
\hline 17 & 0.45 & 8.88 & 4.92 & $80.0 \pm 0.6 b$ & $133.3 \pm 1.0 \mathrm{~b}$ \\
\hline 18 & 2.23 & 8.88 & 4.92 & $76.7 \pm 1.3 \mathrm{c}$ & $127.8 \pm 2.2 \mathrm{c}$ \\
\hline 19 & 0 & 22.20 & 0 & $23.3 \pm 0.3 \mathrm{gh}$ & $38.8 \pm 0.6 \mathrm{gh}$ \\
\hline 20 & 0.45 & 22.20 & 0 & $30.3 \pm 0.9 \mathrm{gh}$ & $50.5 \pm 1.5 \mathrm{gh}$ \\
\hline 21 & 2.23 & 22.20 & 0 & $31.0 \pm 0.6 \mathrm{f}$ & $51.7 \pm 1.0 \mathrm{f}$ \\
\hline 22 & 0 & 22.20 & 2.46 & $38.3 \pm 0.9 \mathrm{f}$ & $63.9 \pm 1.5 \mathrm{f}$ \\
\hline 23 & 0.45 & 22.20 & 2.46 & $24.0 \pm 2.1 \mathrm{i}$ & $40.0 \pm 3.5 \mathrm{i}$ \\
\hline 24 & 2.23 & 22.20 & 2.46 & $22.3 \pm 1.5 \mathrm{i}$ & $37.2 \pm 2.4 \mathrm{i}$ \\
\hline 25 & 0 & 22.20 & 4.92 & $25.0 \pm 2.1 \mathrm{~h}$ & $41.7 \pm 3.5 \mathrm{~h}$ \\
\hline 26 & 0.45 & 22.20 & 4.92 & $21.3 \pm 1.5 \mathrm{ij}$ & $35.6 \pm 2.4 \mathrm{ij}$ \\
\hline 27 & 2.23 & 22.20 & 4.92 & $22.0 \pm 1.5 \mathrm{ij}$ & $36.7 \pm 2.6 \mathrm{ij}$ \\
\hline
\end{tabular}

Values presented as mean $\pm \mathrm{SE}$, with different letters within a column to indicate significant differences at the 0.05 level. There are 15 explants for each treatment. Each experiment was repeated three times and the differences between the means were compared by Duncan's multiple range tests.

$\mathrm{NAA}=$ naphthalene acetic acid; 6-BA = 6-benzylaminopurine; IBA $=3$-indolebutyric acid .

Table 3. Test of between-subjects effects.

\begin{tabular}{llrrrrr}
\hline Dependent variables & \multicolumn{1}{c}{ Source } & $\begin{array}{c}\text { Type III sum } \\
\text { of squares }\end{array}$ & $\begin{array}{c}\text { Degrees } \\
\text { of freedom }\end{array}$ & Mean square & $F$ value & Significance \\
\hline Differentiation rate & Corrected model & $12,129.4^{\mathrm{z}}$ & 6 & $2,021.6$ & 17.0 & 0.000 \\
& Intercept & $41,827.1$ & 1 & $41,827.1$ & 350.7 & 0.000 \\
& NAA & 95.3 & 2 & 47.7 & 0.4 & 0.676 \\
& 6-BA & $11,089.0$ & 2 & $5,544.5$ & 46.5 & 0.000 \\
& IBA & 945.1 & 2 & 472.5 & 4.0 & 0.036 \\
& Error & $2,385.4$ & 20 & 119.3 & & \\
& Total & $56,342.0$ & 27 & & & \\
& Corrected total & $14,514.9$ & 26 & & & \\
Proliferation rate & Corrected model & $33,682.1^{\mathrm{y}}$ & 6 & $5,613.7$ & 17.0 & 0.000 \\
& Intercept & $116,112.0$ & 1 & $116,112.07$ & 351.0 & 0.000 \\
& NAA & 264.4 & 2 & 132.2 & 0.4 & 0.676 \\
& 6-BA & $30,780.7$ & 2 & $15,390.4$ & 46.5 & 0.000 \\
& IBA & $2,637.0$ & 2 & $1,318.5$ & 4.0 & 0.035 \\
& Error & $6,615.6$ & 20 & 330.8 & & \\
& Total & $156,409.7$ & 27 & & & \\
\hline
\end{tabular}

${ }^{\mathrm{z}} R^{2}=0.836$ (adjusted $R^{2}=0.786$ ).

${ }^{\text {y }} R^{2}=0.836$ (adjusted $R^{2}=0.787$ ).

$\mathrm{NAA}=$ naphthalene acetic acid; 6-BA = 6-benzylaminopurine; IBA $=3$-indolebutyric acid.

\section{Conclusion}

By inducing stem node, the whole plantlets of $S$. splendens 'Cailinghong' could be rapidly regenerated, without an intervening callus phase. Different PGRs' combinations and concentrations exhibited significant effects on bud induction. The optimum condition is $1 / 2 \mathrm{MS}$ medium supplemented with $0.45 \mu \mathrm{M}$ NAA, 8.88 $\mu \mathrm{M}$ 6-BA, and $2.46 \mu \mathrm{M}$ IBA for shoot multiplication, and 1/4 MS medium supplemented with $2.23 \mu \mathrm{M}$ NAA for root induction.
Table 4. Effect of different concentrations of NAA on adventitious root induction of Salvia splendens 'Cailinghong'.

\begin{tabular}{lr}
\hline NAA concentrations $(\mu \mathrm{M})$ & $\begin{array}{c}\text { Root induction } \\
\text { frequency }(\%)\end{array}$ \\
\hline 0 & $1.3 \pm 0.2 \mathrm{~b}$ \\
2.23 & $90.0 \pm 0.2 \mathrm{a}$ \\
4.46 & $89.5 \pm 0.3 \mathrm{a}$ \\
11.15 & $90.1 \pm 0.6 \mathrm{a}$ \\
22.29 & $89.7 \pm 1.9 \mathrm{a}$ \\
\hline
\end{tabular}

Values presented as mean \pm SE, with different letters within a column to indicate significant differences at the 0.05 level.

NAA $=$ naphthalene acetic acid. 


\section{Literature Cited}

Duncan, D.B. 1955. Multiple range and multiple F tests. Biometrics 11:1-42.

Fu, Q.J., G.Z. Shen, C. Yi, and H.P. Zhao. 2009. A new scarlet sage cultivar 'Shenzhouhong'. Acta Hort. Sinica 36:1557-1558.

Guo, Q.Y., P. Wang, and Z.P. Liu. 2012. Effect of IBA and 6-BA ratio on adventitious shoot induction from hypocotyl in soybean. Soybean Sci. 31:725-730.

Han, X., X. Qiu, and B. Wang. 2006. Tissue culture and rapid propagation of stem node of Phyllanthus urinaria L. Plant Physiol. Commun. 42:679.

Hui, C.M., X. Han, Z.H. Liang, C.Y. Zheng, C.Y. Ma, and L.B. Liu. 2004. A new variety of scarlet sage- 'Zhongchuanhong'. Acta Hort. Sinica 31:281.

Lai, Z.X., C.C. Lai, H.W. Yan, Q.Y. Sang, W.Y. Guo, H.M. Wu, and D.M. Pan. 2001. Micropropagation technique of dwarf Salvia splendens. J. Fujian Agr. Univ. 30:483-485.

Liu, H., G.P. Zhang, G.Z. Shen, S.L. Ruan, and Q.J. Fu. 2012. Callus induction and plant regeneration from mature seeds of Salvia splendens. Intl. J. Agr. Biol. 14:445-449.

Jiménez, V.M., J. Castillo, E. Tavares, E. Guevara, and M. Montiel. 2006. In vitro propagation of the neotropical giant bamboo, Guadua angustifolia
Kunth, through axillary shoot proliferation. Plant Cell Tissue Organ Cult. 86:389-395.

Mallón, R., J. Rodríguez-Oubiña, and M.L. González. 2011. Shoot regeneration from in vitro-derived leaf and root explants of Centaurea ultreiae. Plant Cell Tissue Organ Cult. 106:523-530.

Maruthi Rao, A., I. Sampath Kumar, and P. Kavi Kishor. 2012. Effect of growth regulators and physiological gradients on the high frequency plant regeneration from the long-term callus cultures of different germplasms of rice (Oryza sativa L.). J. Phycol. 4:6-15.

Murashige, T. and F. Skoog. 1962. A revised medium for rapid growth and bio assays with tobacco tissue cultures. Physiol. Plant. 15:473-497.

Purkayastha, J., T. Sugla, A. Paul, S. Solleti, and L. Sahoo. 2008. Rapid in vitro multiplication and plant regeneration from nodal explants of Andrographis paniculata: A valuable medicinal plant. In Vitro Cell. Dev. Biol. Plant 44:442-447.

Song, J.Y., N.S. Mattson, and B.R. Jeong. 2011. Efficiency of shoot regeneration from leaf, stem, petiole and petal explants of six cultivars of Chrysanthemum morifolium. Plant Cell Tissue Organ Cult. 107:295-304.

Soundararajan, P., I. Sivanesan, E.H. Jo, and B.R. Jeong. 2013. Silicon promotes shoot proliferation and shoot growth of Salvia splendens under salt stress in vitro. Horticulture, Environment, and Biotechnology 54:311-318.

Sugiyama, M. 1999. Organogenesis in vitro. Curr. Opin. Plant Biol. 2:61-64.

Sun, Y., D. Zhang, and J. Smagula. 2010. Micropropagation of Ilex glabra (L.) A. Gray. HortScience 45:805-808.

Tu, R.P., J.Y. Hu, Q.Q. Ji, G.H. Xia, and B.S. Zheng. 2014. Highly efficient in vitro adventitious shoot regeneration of Adenosma glutinosum (Linn.) Druce using leaf explants. Afr. J. Biotechnol. 11:7542-7548.

Werbrouck, S.P., B. van der Jeugt, W. Dewitte, E. Prinsen, H.A. Van Onckelen, and P.C. Debergh. 1995. The metabolism of benzyladenine in Spathiphyllum floribundum 'Schott Petite' in relation to acclimatisation problems. Plant Cell Rpt. 14:662-665.

Werbrouck, S.P., M. Strnad, H.A. Van Onckelen, and P.C. Debergh. 1996. Meta-topolin, an alternative to benzyladenine in tissue culture? Physiol. Plant. 98:291-297.

Zhang, Y.N., C. Qian, and L.X. Chen. 2010. Primary development of tissue culture systems for stem of Demdrobium nobile. Northern Hort. 8:129-131.

Zhi, L.T., P.P. Hong, H.W. Chen, H.L. Wang, and K.F. Liu. 2013. Effects of applying exogenous plant hormone on lateral bud growth of Salvia splendens. Northern Hort. 7:52-59. 